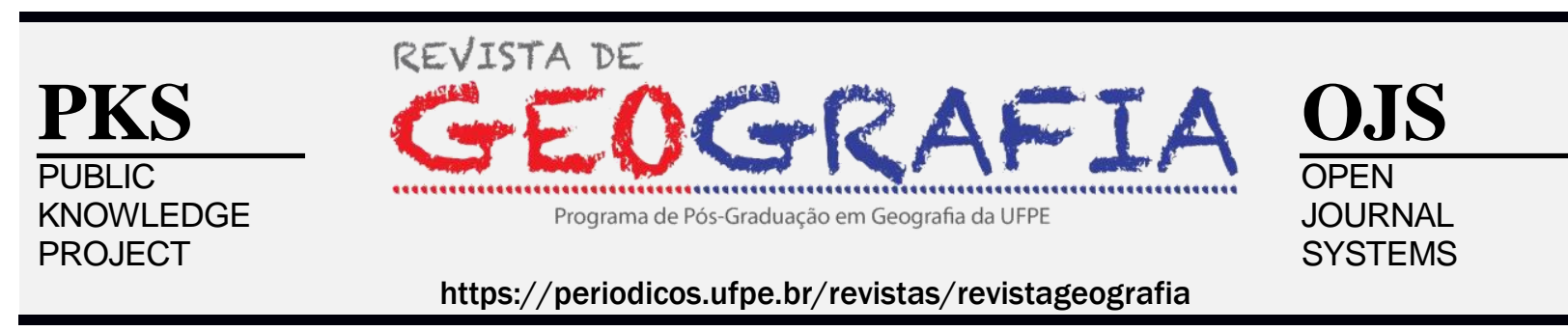

\title{
A FORMAÇÃO SOCIOESPACIAL BRASILEIRA NA VISÃO DE MILTON SANTOS
}

\author{
Vivian Costa Brito ${ }^{1}$, Ronaldo Leão de Miranda $^{2}$, Ivo Marcos Theis ${ }^{3}$, Gilberto Friedenreich dos \\ Santos \\ 1 - Doutoranda em Desenvolvimento Regional pela Universidade Regional de Blumenau - \\ vivianbritofoz@gmail.com \\ 2 - Mestre em Desenvolvimento Regional pela Universidade Regional de Blumenau - \\ ronaldo_leaomiranda@hotmail.com \\ 3 - Professor do Programa de Pós-Graduação em Desenvolvimento Regional da Universidade Regional de \\ Blumenau - ivotheis@gmail.com \\ 4 - Professor do Programa de Pós-Graduação em Desenvolvimento Regional da Universidade Regional de \\ Blumenau-gilbertofrieden@gmail.com
}

Artigo recebido em 23/12/2018 e aceito em 25/11/2019

\begin{abstract}
RESUMO
Este artigo tem por objetivo situar Milton Santos nos estudos sobre a formação social do Brasil, desde a obra, $O$ Brasil: território e sociedade no início do século XXI. Milton Santos e María Laura Silveira introduzem uma nova dimensão para entender a formação do território brasileiro, de caráter espacial, pelas categorias formação socioespacial e território usado. O estudo da formação do território brasileiro, objeto central deste artigo, é examinado pelas duas partes da obra, que se compromete fazer uma análise do território brasileiro, seguida de uma síntese. A análise é consubstanciada pelas mudanças no território pelo advento das técnicas (objetos e ações), refletidas na passagem de um meio natural para um meio técnico, e na conformação de um meio técnico-científicoinformacional, diante dos avanços do processo de globalização.
\end{abstract}

Palavras-chave: Formação socioespacial. Meio técnico-científico-informacional. Territorio usado. Brasil.

\section{THE BRAZILIAN SOCIOESPACIAL FORMATION IN THE VISION OF MILTON SANTOS}

\section{ABSTRACT}

This article aims to situate Milton Santos in studies about the social formation of Brazil, since the work, Brazil: territory and society at the beginning of the 21 st century. Milton Santos and María Laura Silveira introduce a new dimension to understand the formation of the Brazilian territory, of spatial character, by the socio-spatial formation categories and territory used. The study of the formation of the Brazilian territory, the central object of this article, is examined by both parts of the work, which undertakes to make an analysis of the Brazilian territory, followed by a synthesis. The analysis is consubstantiated by changes in the territory by the advent of techniques (objects and actions), reflected in the transition from a natural environment to a technical environment, and in the conformation of a technical-scientific-informational environment, in the face of the advances of the globalization process.

Keywords: Socio-spatial formation. Technical-scientific-informational medium. Territory used. Brazil. 


\section{INTRODUÇÃO}

Este artigo tem por objetivo apresentar o legado de Milton Santos para o Pensamento Social Brasileiro, sobre a ótica da dinâmica globalização. Sua inserção enquanto pensador social brasileiro se dá pela publicação em 2001 do livro O Brasil: território e sociedade no início do século XXI, sua última obra. Não obstante à sua contribuição a construção de uma geografia crítica brasileira, com mais de 300 artigos e 40 livros, em especial a instituição de novas categorias de análise no âmbito da geografia - totalidade, forma, função, estrutura, processo, formação socioespacial e a ênfase dada ao território e lugar. Disseca a natureza do espaço geográfico e perfaz uma nova forma de se periodizar a formação social brasileira a partir dos aspectos técnicos, científicos e informacionais.

Esse confronto entre sua epistemologia criada e sua base de análise empírica, é sintetizado na diferenciação que o autor traça entre território (abstrato) e território usado (concreto). Revela como fazer a análise numa perspectiva multidisciplinar, não se limitando a um enfoque setorial. Destarte, é preciso compreender que esse esforço soma-se às demais contribuições proferidas por Celso Furtado no livro Formação Econômica do Brasil, Caio Prado Júnior na obra Formação do Brasil Contemporâneo, e muitos outros intelectuais que nos ofereceram uma nova perspectiva de pensar o Brasil a partir do Brasil.

Muitas foram as classificações elaboradas de suas obras. Com destaque ao recorte temático feito por Elias (2002), e a imbricação espaço temporal da biografia feita por sua esposa (SANTOS, s.d.). Nesse sentido, outros pesquisadores merecem destaque. Silva (2002), colaboradora direta em seu Laboratório de Geomorfologia da Universidade Federal da Bahia (UFBA), e os escritos de Ribeiro (2002). Nesse artigo essas contribuições são absorvidas e dispostas em uma estrutura que busca situar o Ser Milton Santos no Estar no mundo em constante movimento, evitando uma periodização linear, mas que abranja a complexidade de suas obras e as trajetórias por ele empreendidas.

Inicialmente é exposta a trajetória de vida do autor, seguida da síntese de suas obras, através de cinco recortes de estudos: regionais sobre Salvador e a Bahia; sobre a urbanização dos países subdesenvolvidos; epistemológicos em geografia; sobre o território brasileiro; e sobre a globalização econômica. Abre-se uma seção a parte para tratar da obra: $O$ Brasil: território e sociedade no início do século XXI, com o propósito de situar sua contribuição para o Pensamento Social Brasileiro. Destarte, é traçada a influência desse autor para os demais pesquisadores e as considerações que podem ser tecidas em torno de seu pensamento. 


\section{MILTON SANTOS: VIDA E OBRA}

\section{VIDA}

A observação do movimento é o marco inicial que leva Milton Santos a se aproximar da Geografia, mesmo tendo enveredado por uma formação em Direito na UFBA em 1948. Esse olhar para o que ocorria no território brasileiro no século XX é um tanto perspicaz, pois ao mesmo tempo em que o Brasil se construía como unidade nacional, havia um profundo movimento de objetos e pessoas no território em direção a Região Concentrada. Nascido em Brotas de Macaúbas em 1926, interior da Bahia, sua primeira base de formação foi familiar.

A genealogia materna tinha trajetória exitosa na docência primária, e a paterna o legado do processo de escravidão. Com o tio a orientação para carreira de direito. A família muda-se para Alcobaça no Estremo Sul da Bahia. É onde conclui o ensino primário. Com a mãe apendeu a ler, escrever e o francês. Seu irmão Nailton, se forma em Direito, e sua irmã Yeda em Medicina. Segue para Salvador e é aceito no tradicional colégio Instituto Baiano de Ensino. O interesse pelo conhecimento o fez criar o jornal "O Farol” e sua atuação política perpassa a vice-presidência da União Nacional dos Estudantes, a criação do Partido Estudantil Popular e da Associação Brasileira de Estudantes Secundaristas.

Entretanto o interesse pelo movimento e pelo escopo de estudo e análise da Geografia o fez enveredar por outro caminho. Assim torna-se professor de Geografia Humana nos colégios ICEIA, Colégio Central em Salvador e Ginásio Municipal em Ilhéus. Atividade que realizava em paralelo com sua função de jornalista e redator do Jornal A TARDE (1954-1964). Em Ilhéus produziu diversos artigos e o livro "A Zona do Cacau”. Local também em que conheceu sua primeira esposa Jandira Rocha, mãe de seu primeiro filho, Milton Santos Filho, que segue a carreira de Economia e torna-se catedrático da UFBA.

O segundo casamento foi com Marie Hélène no Haiti em 1972, com quem tem mais um filho (Rafael) e fica até a sua morte. Passa a lecionar a disciplina de Geografia Humana na Faculdade Católica de Filosofia (1956-1960), cadeira que assume também na UFBA (19591964), onde cria o Laboratório de Geomorfologia e Estudos Regionais da UFBA. Entre 1948 e 1964 desenvolve uma série de estudos e diagnósticos sobre Salvador e o Estado da Bahia com mais de 60 títulos entre livros e artigos. Destarte, enveredou sobre os temas da política econômica e planejamento regional, sendo representante da Casa Civil do presidente Jânio Quadros na Bahia (1961) e presidente da Fundação Comissão de Planejamento Econômico do Estado da Bahia (1962-1964). 
Com participação ativa junto à comunidade científica na promoção de eventos científicos, aproxima sua intensa produtividade e o seu pensamento de grandes geógrafos franceses da época. O mais importante foi Jean Tricart, posterior orientador de sua tese de doutorado no Instituto de Geografia da Universidade de Strasbourg na França, intitulada: $O$ Centro da Cidade de Salvador. Através de Tricart estabeleceu profunda Cooperação Técnica entre a Bahia e a França. Isso reflete em toda uma concepção da ciência geográfica na Bahia que avança em direção à reflexão não se limitando somente à técnica, influência esta que transcende para a comunidade científica no Brasil e América Latina, e em 1963 o leva ao cargo de presidente da Associação de Geógrafos Brasileiros (AGB).

Sua relação com a França se torna profunda, e quando a condição política em função da ditadura lhe impôs uma retirada do país, recebeu de Van Der Haegen o apoio para ir se refugiar na França. Além disso, fomentou a qualificação de muitos professores no exterior em especial na França e na África. É com base na Escola da Geografia Crítica francesa que passa a embasar seu conhecimento e construir o legado de uma Geografia Crítica brasileira, a ser compreendido pela extensão de suas obras.

No período de 1964 a 1977 em que esteve exilado conheceu múltiplas realidades, desde os países de primeiro mundo, enquanto professor nas universidades: Toulouse, Bordeaux e Paris-Sorbonne, Toronto (Canadá), Columbia University (New York), dentre outros. Contudo foram as experiências em países do terceiro mundo,que o fizeram avançar os estudos para uma epistemologia da urbanização nos países subdesenvolvidos e da própria geografia. Lecionou em Caracas (Venezuela), Dar-es-Salam (Tanzânia), Instituto de Estudos do Desenvolvimento Econômico e Social (Moçambique), e criou o Laboratório de Geografia na Nigéria.

Seu retorno ao Brasil em 1977 não coincide com a retomada das atividades docentes na UFBA, que não o aceita. São as atividades de consultoria nas Regiões Sul e Sudeste que lhe abrem portas para ser professor assistente na Universidade Federal do Rio de Janeiro (19791983). Em 1984 ingressa como professor titular de Geografia Humana na USP, criando um laboratório de pesquisa similar ao da UFBA, e permanece até sua aposentadoria. Aliado ao trabalho docente, em 1990 continua a produção de seus artigos jornalísticos, através da Folha de São Paulo. Engajado politicamente assume entre 1991 e 1993 a presidência da Associação Nacional de Pós-Graduação em Pesquisa e Planejamento Urbano e Regional (ANPUR), e entre 1993 a 1995 como presidente da Associação Nacional de Pós-Graduação e Pesquisa em Geografia (ANPEGE). 
Em 1994 recebe o Prêmio Internacional Vautrin Lud pelo teor de suas obras. Em 1995 a UFBA o acolhe de volta. Em 1997 recebe o Prêmio Jabuti pela obra A natureza do espaço, Técnica e Tempo. Razão e Emoção, melhor livro de Ciências Humanas. Destarte, foram mais de 20 títulos Honoris Causa de universidades no Brasil e no exterior.

\section{OBRA}

Milton Santos merece um preâmbulo de modo a situar dois caminhos por ele percorridos (ELIAS, 2002): um em direção a uma epistemologia sobre a natureza do espaço geográfico e o outro de natureza empírica, com ênfase às categorias território e lugar. Esse recorte de suas obras oferece um sentido apropriado para esta análise, já que constrói o arcabouço teórico e conceitual, com qual vai estudar as transformações no território brasileiro. Um ponto chave na construção do pensamento social brasileiro de Milton Santos é que ele constrói as próprias categorias de análise, em especial a categoria socioespacial.

Do ponto de vista de uma teoria geográfica, o espaço é concebido como a categoria principal para se entender o território, através das categorias: forma, função, estrutura, processo e totalidade. Compreende que a análise geográfica do espaço deve considerar o caráter dinâmico do mesmo, que contém estruturas organizadas por meio de formas e funções que se altera com o desenvolvimento de cada sociedade. O espaço, portanto, passa a ser visto parte social, como teia de relações, daí a definição de "categoria de formação socioespacial".

Sua perquirição sobre a construção de uma geografia crítica o leva a conceber a mesma como "filosofia das técnicas", que inclui uma relação dialética entre as ordens global e local. Uma nova racionalidade, tendo como sustentáculo as normas, como meio para disseminar a homogeneização técnica e organizacional. A globalização vai se configurar materialmente através do meio técnico-científico-informacional. Um processo que envolve o meio natural, o meio técnico e o meio técnico-científico-informacional, como o hodierno sistema temporal sobre o qual institui a periodização da formação "socioespacial” brasileira.

A primeira classificação refere-se aos Estudos urbanos regionais sobre Salvador e a Bahia, um olhar de quem vê de perto a formação da primeira rede urbana estruturada das Américas, o que confere uma análise peculiar sobre o centro da cidade de Salvador, sua tese de doutorado. No final da década de 1950, Milton Santos passa a se dedicar aos estudos sobre Salvador e a Bahia. Escreve em 1948 o livro O povoamento da Bahia: suas causas econômicas. Em 1953 Os estudos regionais e o futuro da geografia e os Estudos sobre geografia. Em 1957 
Zona do Cacau, que incita a substituição da monocultura pelas autoridades e proprietários de terra.

Em 1958 publica Estudos de Geografia da Bahia, em parceria com Jean Tricart e outros autores. No mesmo ano Localização Industrial, sobre os estudos e problemas da Bahia. Em 1958 sua tese de doutorado: O Centro da Cidade do Salvador, um clássico da Geografia mundial. Em 1959 os livros: A cidade como centro de região e A rede urbana do Recôncavo. Em 1960 lança o livro Marianne em Preto e Branco, fruto de seus estudos na África e em que estabelece um comparativo com a realidade francesa.

Num segundo momento vai ao encontro dos estudos da urbanização dos países subdesenvolvidos, mais precisamente sobre os países subdesenvolvidos na América Latina e na Àfrica, em direção à teorização em Geografia. Procura compreender a dinâmica da desigualdade e seus efeitos no território, com ênfase na estrutura interna da cidade, dos processos de urbanização e da rede urbana nesses paises. Em 1965 escreve A cidade nos países subdesenvolvidos, voltado para a temática da urbanização. Em 1967 escreve Croissance démographique et consommation alimentaire dans les pays sous-développés, sobre o crescimento demográfico e o consumo de alimentos em países subdesenvolvidos.

Em 1969 o livro Aspects de la géographie et de l'économie urbaine des pays sousdéveloppés, que trata dos aspectos da geografia e das economias urbanas nesses países. Em 1970 a obra Dix essais sur les villes des pays-sous-développé, que trata das cidades dos países subdesenvolvidos. Em 1971 O trabalho do geógrafo no Terceiro Mundo publicado no Brasil em 1978, em que compreende o papel do intelectual: o de criar o desconforto. Em 1972 escreve no Canadá o livro Underdevelopment and poverty: a geographer's view, discutindo a relação entre subdesenvolvimento e a pobreza sobre o olhar do geógrafo.

Em 1971 As cidades do terceiro mundo, para entender a dinâmica da economia urbana nos paises subdesenvolvidos, inspirando o livro em 1975, O espaço dividido: os dois circuitos da economia urbana publicado no Brasil em 1978. Nesta obra divide o espaço em dois circuitos, um superior de "capital intensivo" e um inferior de "trabalho intensivo", com o papel central das modernizações na ordem temporal da organização do espaço, sobretudo no Terceiro Mundo. A pobreza urbana é lançado em 1978 com críticas às teorias sobre a pobreza. Nesse mesmo ano produz Economia espacial: críticas e alternativas, na qual admoesta as teorias do polo de desenvolvimento, lugares centrais, polo, periferia, das difusões de inovações e a ênfase dada ao planejamento, pois considera que as mesmas servem de sustentáculo para o sistema econômico e da estrutura de classes dominantes nos países subdesenvolvidos. 
Em 1980 publica A urbanização desigual. Estuda o fenômeno da urbanização nos países desenvolvidos e subdesenvolvidos para entender os ritmos de urbanização e seus mecanismos. Em 1991 escreve Manual de geografia urbana, um marco de análise da Geografia Urbana no Brasil, que oferece um arcabouço conceitual e metodológico capaz de fazer compreender os processos de crescimento urbano e suas consequências. Em 1982 publica Ensaios sobre a Urbanização Latino-americana, obra que discute as noções de desenvolvimento e subdesenvolvimento aplicadas na América Latina na década de 1960, com estudos de casos na Colômbia, Venezuela, México e Peru. Finalmente escreve Espaço e sociedade em 1979.

Uma terceira classificação está vinculada aos Estudos epistemológicos em geografia, de uma Geografia Humana para uma Geografia Crítica no Brasil, preocupada mais com a gênese do território do que sua forma. Surge com o texto Sociedade e Espaço: a formação social como teoria e como método em 1977, que resulta na obra Por uma geografia nova: da crítica da Geografia a uma Geografia Crítica de 1978, referência mundial sobre o tema. Aborda as categorias forma, função, estrutura e processo. Em 1982 publica Pensando o espaço do homem, que discute o papel da ciência e da tecnologia, a totalidade como componente do método e o homem/sociedade como agente/sujeito no estudo da totalidade, tempo e espaço.

Em Espaco e Método de 1985 aprofunda as relações entre técnica e espaço, o espaço entendido dialeticamente como campo de força, traduzido como técnico-científicoinformacional, capaz de entender o papel do mesmo na tecitura da totalidade social exigindo nova periodização para se compreender o passado e o presente. Em Metamorfoses do Espaço Habitado de 1988 aborda o mesmo tema, diferencia a paisagem do espaço, dando ênfase ao catater dinâmico do espaço, em função do movimento, e fulgaz da paisagem, por conter um instante tangivel da sociedade. A espacialidade é definida pelo caráter funcional e o espaço; pelo aspecto estrutural. As contradições do espaço geográfico são estudadas a partir dos conceitos de fixos e fluxos, através dos circuitos espaciais da produção.

Em Técnica, Espaço, Tempo: globalização e meio técnico-científico informacional de 1994 expõe que o meio técnico-científico-informacional explica os efeitos do processo da globalização no território. Cria a noção de sistemas de objetos e sistemas de ações e apresenta as três unicidades que favorecem a globalização: a unicidade técnica, a convergência dos momentos e a unicidade do motor, que são as mesmas produtoras do processo de fragmentação. Discute a totalidade empírica vinculada a uma natureza artificializada. Em A Natureza do Espaço. Técnica e Tempo. Razão e Emoção de 1996 faz uma síntese de todo o conteúdo apresentado nas demais obras, reforçando o papel do espaço para a construção da teoria social, 
principalmente a força do lugar e seus elementos territoriais endógenos vinculados com o processo da globalização.

Uma quarta classificação versa sobre os estudos sobre o território brasileiro presente em sua análise desde 1950, em especial sobre o Estado de São Paulo e a metrópole paulistana. Em 1986 publica o projeto O Centro Nacional: crise mundial e redefinição da Região Polarizada, em que analisa o papel da técnica e da ciência na configuração da crise econômica mundial e nas alterações da estrutura territorial, que se evidencia com a divisão territorial e social do trabalho. Mudanças essas com efeitos nas atividades econômicas, nos recursos financeiros e na população brasileira. Propõe uma reconfiguração da divisão regional do país que reflita a realidade nacional. Cria o conceito de Região Concentrada.

Procura estabelecer as condicionantes do espaço em múltiplas escalas, os viezes de modernização, com estudos regionais para entender a reorganização espacial do Estado de São Paulo e as mudanças no processo de urbanização. A Metrópole corporativa fragmentada: o caso de São Paulo de 1990 qualifica São Paulo como uma Cidade Mundial, a partir de condicionantes, do papel da ciência, da tecnologia e da informação, sendo esta um modelo no Terceiro Mundo. Em A urbanização brasileira de 1993 traça as bases de contribuição ao pensamento social brasileiro. Realiza um estudo sobre a evolução do território e da urbanização no país. Quebra a dicotomia entre o rural e urbano e explica que há "um Brasil urbano (incluindo áreas agrícolas) e um Brasil agrícola (incluindo áreas urbanas)” (SANTOS, 1993, p. 37).

Discute também os processos de involução metropolitana em diversas metrópoles brasileiras, notadamente da metrópole de São Paulo. Relaciona isso com a formação de um exército industrial de reserva de lugares, ampliando a fragmentação do território e conformando uma nova divisão social e territorial do trabalho. Como resultado de análise compreende que a urbanização do Brasil se caracteriza por ser corporativa, com desigual arranjo do meio técnicocientífico-informacional, atuando seletivamente no espaço. Em 1994 faz um estudo empírico sobre a urbanização do Brasil em Por uma economia política da cidade, em especial da metrópole de São Paulo. Em 2001 O Brasil: território e sociedade no início do século XXI, sua última obra e objeto de análise central deste artigo.

A última classificação se refere aos seus estudos sobre a globalização econômica em $O$ Espaço do Cidadão em 1987 e Por uma outra globalização: do pensamento único à consciência universal em 2000, ambas com um posicionamento politico do autor voltado para a construção da cidadania e da ética, sustentado na crítica ao consumismo atual. A primeira obra foi escrita no momento em que o Brasil estabelecia os debates sobre a nova Constituição Brasileira. A 
segunda obra discute a globalização numa perspectiva de revolução burguesa, na forma de um globalitarismo, expressão que reflete a fusão de globalização com totalitarismo. Apresenta aspectos positivos da globalização, pois faz emergir à escala mundial os movimentos sociais, as ideologias contrárias à mesma, e um sentimento de necessidade de mudança.

No entanto essa é uma visão romântica, em achar que haverá uma maior solidariedade local e solidariedade horizontal em detrimento à atuação verticalizada e imperativa do capital hegemônico, através da alta participação popular na tomada de decisões.

\section{O BRASIL: TERRITÓRIO E SOCIEDADE NO INÍCIO DO SÉCULO XXI}

Obra escrita por Santos e Silveira (2001), é uma síntese da construção epistemológica, conceitos e categorias elaborados por Milton Santos em A Natureza do Espaço. Técnica e tempo. Razão e emoção (1996), aplicadas à análise empírica do espaço geográfico que explica a formação do Brasil pelo próprio território. Objetiva oferecer uma interpretação geográfica do Brasil ao leitor comum e, servir de guia de trabalho para os estudiosos.

Contrapõem a epistemologia da época em tratar de modo macro a questão nacional e assumem a difícil tarefa de explicar um território de dimensões continentais e com abissais disparidades regionais. Como elemento agravante tem-se uma arena política alicerçada pelo neoliberalismo, com profundas transformações territoriais, oriundas da abertura comercial e de intenso processo de industrialização, que fragmenta ainda mais o território, exigindo uma metodologia que ao mesmo tempo pudesse dar conta das especificidades regionais e atender ao estudo do território brasileiro em sua totalidade. Para isso, foram utilizadas como eixo central as categorias território usado e formação socioespacial.

O território usado, sinônimo de espaço geográfico, abarca todos os atores (objetos e ações), não tendo um viés setorial econômico, envolvendo os componentes híbridos: a materialidade e a vida social. O território usado funciona como norma, que influi na ação presente. A formação socioespacial inclui a dimensões: econômica, social e espacial, e nos oferece a compreensão do território em sua totalidade, pois nos ajuda a entender os processos, pelo uso da teoria da mediação, que imbrica fatos e relações relevantes, entre o passado e o presente.

Pensando o território como ator, o mesmo é analisado através da divisão territorial do trabalho, que denota a estreita relação espacial das empresas, com formação de hierarquia entre lugares. Decorrentes de mudanças na divisão internacional do trabalho que implicam novos 
usos no território superpondo usos pretéritos. Ainda, os estudos dos círculos espaciais da produção, que relacionam ao lugar, a um fragmento do espaço no conjunto da divisão do trabalho do território; e dos círculos de cooperação, que estabelecem vínculos e trocas interregionais intensas, capaz de explicar a hierarquia dos lugares em múltiplas escalas.

Fugindo de uma análise geográfica que se limita a uma mera distribuição geográfica de um fenômeno, o território usado é concebido a base da vida social e a principal categoria de análise do livro. O território usado apresenta usos múltiplos, um arranjo espacial repleto de descontinuidades na escala regional, defasagens e superposições de divisão do trabalho sociais e territoriais, que nos ajudam a entender as desigualdades regionais. Pois, não há um movimento contínuo e uniforme dos processos de modernização e dos atores dinâmicos, que dependem do contexto de cada região e da necessidade de novas racionalidades, não podendo ser acrítica a outras práticas territoriais, sem considerar o território em questão, pois é nele que estão as bases de construção das mesmas.

Assim, definem a análise do território a partir do estudo da evolução dos sistemas técnicos, compostos de objetos e ações, formas de fazer e regular, que ajudam a entender o modo, a finalidade, os atores, o momento, a forma e a distribuição do trabalho, o local em que o território é usado. Procuram entender as funções do novo espaço geográfico e o papel das formas geográficas materiais, sociais, jurídicas e políticas - reguladas pelo mercado, impregnadas de ciência, técnica e informação.

A obra está dividida em duas grandes partes, a primeira faz uma análise do território brasileiro e na segunda parte uma síntese. Esse recorte procura ver as mudanças quantitativas e qualitativas por que passou o território, a fim de antecipar tendências "o que é novo no espaço e como se combina com o que já existia" (Ibidem, 2001, p. 11). Na primeira parte é feita uma divisão da formação social do Brasil em três períodos, que remete as transformações ocorridas no espaço geográfico - formação socioespacial, pelos aspectos técnico, científico e informacional. O período dos "meios naturais" ou pré-técnico, em que a natureza era quem delimitava o ritmo do desenvolvimento, através do tempo lento da natureza e pela ocupação dos europeus (Séc. XVI, XVII e XVIII), e sua necessidade de adaptar-se aos sistemas naturais, a exemplo da cultura açucareira no Nordeste.

Perpassando, a um período dos meios técnicos de mecanização incompleta e produção mecanizada, mas dependente do trabalho direto e concreto do homem, com pouco capital inserido na natureza. Abarca ainda, o meio técnico da circulação mecanizada e dos inícios da industrialização na primeira metade do século XX, e da urbanização interior e da formação da 
Região Concentrada. Uma economia voltada para o estrangeiro, promovendo o crescimento desigual das cidades. Tem como elo de integração e circulação o desenvolvimento dos sistemas de transportes e comunicações, mas não constitui uma rede urbana nacional, e sim, voltada entre as Regiões Sul e Sudeste. É com o progresso das telecomunicações e energia financiado pelo Estado que ocorre a integração de áreas distantes.

Surge a rede brasileira de cidades, formando uma hierarquia nacional, um urbanismo de interior, e o início do processo de integração nacional, com a hegemonia de São Paulo. Formase um mercado Centro-sul, com crescimento demográfico do país e das cidades, pelas migrações da população das áreas rurais para as áreas urbanas, porém com as mesmas estruturas sociais. O tempo a ser retratado é o tempo lento, centrípeto e um tempo rápido, voltado para fora, centrífugo.

A integração nacional passa a ocorrer integralmente pós-segunda guerra mundial em 1945, com o desenvolvimento dos transportes (Rio-Bahia) e das demandas de modernização industrial. Nesse período São Paulo se consolida enquanto hegemonia nacional (produção e distribuição), utilizando as demais áreas do território como mercado, concentrando a maior parcela dos investimentos do Brasil. A hierarquia, baseada na dependência entre São Paulo, centros regionais e metrópoles incompletas. A modernização da agricultura no Sul e Centrooeste. E o deslocamento do centro político para Brasília. Uma relação centro-periferia, em que o polo promove seu modelo de industrialização para demais regiões a fim de beneficiar-se, alicerçado pelo seu sistema financeiro e bancário, resultando na ampliação das desigualdades.

O terceiro período é a conformação de um meio técnico-científico-informacional, concebido como a nova natureza do território, com as mudanças em sua materialidade. $\mathrm{Na}$ década de 1970, pelo desenvolvimento das telecomunicações, transportes e energia dentre outros, e ampliado pela globalização, aprofundaram-se as diferenças regionais já existentes. É sustentado na ideologia do desenvolvimento, consumismo, no crescimento econômico via industrialização e no planejamento, que as ações das políticas e do pensamento social brasileiro traçam os espaços nacionais. Ocorre aumento da migração para o Estado de São Paulo e o enfraquecimento das periferias. As mudanças territoriais, pelas técnicas, sobretudo em função da indústria do petróleo e o surgimento de complexos industriais, tornam o território mais fluido para o neoimperialismo, conduzindo todos os espaços a se aventurarem em escala mundial, com uma integração nacional voltada para este fim.

Isso ocorre de modo seletivo, privilegiando áreas de especialização produtiva, usando elementos públicos em finalidade privada, a exemplo de portos. Essa dinamização que 
prevaleceu historicamente nas regiões centrais e posteriormente chegou às periferias, fez com que pudesse levar o capital, a modernização e cientificização do rural, com alteração na divisão social do trabalho, diminuição da população rural, e a transformação do trabalhador rural em trabalhador volante.

A análise empírica que tem como recorte temporal de 1955 a 1995, denota uma ampliação da concentração geográfica, centralização econômica e de renda, e aumento do setor terciário. O Brasil passa a ser definido como um país subdesenvolvido industrializado, em função das desigualdades regionais (educação, saúde, transporte, comunicações, emprego, tecnologia, ciência, etc.) e de renda profundas, impulsionadas pelo crescimento econômico, empobrecimento das classes sociais, refletindo nos indicadores de PIB e PIB per capita, com severas críticas à política de crescimento, de desenvolvimento e investimento do Estado, voltadas para o mercado, sobretudo, para os setores com maior exportação. É o capital que passa a determinar o território imprimindo sua lógica através de capitais fixos, convertendo trabalho em trabalho abstrato. As desigualdades regionais passam a serem diferenças sociais, com interdependência em múltiplas escalas.

A formação de um contínuum urbano (técnico-científico-informacional) na Região Sul e Sudeste e nos demais espaços geográficos do país como pontos e manchas, ampliando a centralização, agora através das técnicas. Em função da espacialização da produção, traçando o território como o próprio mercado. A integração nacional é traduzida em integração da produção e circulação voltada para o mercado externo.

Desde 1970 há expansão e unificação das técnicas, capaz de usos múltiplos, porém voltadas para a modernização do Sul e Sudeste, com lógica setorial, muitas vezes contrária à demanda regional do país. Ocorre o aumento da mobilidade urbana e de migração, intrarregional e interregional. Surgem os sistemas integrados de monitoramento do espaço geográfico, servindo como controle territorial, convergindo numa "segunda integração territorial" em favor da globalização.

As técnicas sustentam a divisão territorial do trabalho, a propagação de capitais fixos e a circulação de capital especulativo, ampliando a condição de mais valia. Atuam seletivamente em territórios com densidade técnica, nos espaços considerados dinâmicos, alastrando a fragmentação territorial. Essa seletividade na difusão do meio técnico-científico-informacional privilegia umas regiões em detrimento de outras, com a informação, que tem papel central nesse período, passando a ser distribuída de modo desigual sobre o território. É preciso questionar sobre o território, seus atores, seus usos e finalidades. 
Na discusão sobre "A reinvenção dos territórios: perspectivas hegemônicas", PortoGonçalves (2012, p. 27-28) afirma que a revolução tecnológica “[...], não é obra da natureza, mas, sim, instituída por sujeitos determinados em contextos histórico-geográficos específicos e, quase sempre, para resolver problemas bem mundanos." Nesse contexto deve-se considerar que:

\footnotetext{
1- não existe sociedade sem técnica;

2- nem toda sociedade mantém a mesma relação com a técnica;

3- a técnica, sendo um constructo social, não pode ser compreendida fora das relações sociais e de poder que lhes empresta sentido. Portanto, as técnicas não são externas à sociedade que as cria;

4- o sentido das técnicas não é dado por elas mesmas;

5- O sistema técnico é parte das relações sociais e de poder que se realizam praticamente por meio dele.
}

A reestruturação produtiva e a reorganização no território. Desconcentração industrial a partir de 1970. Relocalização das indústrias para as demais regiões do país e do Estado de São Paulo em 1980. As privatizações de estatais, abertura comercial, a busca por consolidar as densidades técnicas, e a "guerra fiscal dos lugares", com elevados gastos públicos na década de 1990. As empresas atraídas pelos baixos salários, sobretudo nas Regiões Norte e Nordeste, sem um compromisso de longo prazo com o território, com severas consequências socioeconômicas e de alteração das estruturas regionais e portuárias para atender as especializações produtivas. A concentração das atividades de serviços na metrópole de São Paulo resultou em diversificação na Região Concentrada e especialização produtiva nas demais áreas. Aumento do desemprego pelo processo de automação das indústrias.

Eclodem mudanças demográficas, a (re) distribuição da população, da economia e geografia do consumo. Aumento populacional e da população economicamente ativa, com menor ritmo nos benefícios sociais. Crescimento das cidades médias, metropolização e interiorização. Aumento dos níveis de vida e a ampliação das desigualdades regionais. Os processos de "involução metropolitana" e de desmetropolização. Ampliação dos setores secundários e terciários. Há concentração do setor terciário nas Regiões Metropolitanas, e elevados índices de desemprego. Melhorias de infraestrutura, com carências nas regiões periféricas. A industrialização concentrada no Sudeste. O nó górdio é a renda, que aumenta sua concentração e ocorre de modo desigual, em favor da Região Concentrada.

Estabelecido o recorte espaço-temporal através das periodizações supracitadas, realizam na segunda parte uma síntese da formação do Brasil, sintetizada na constituição de um espaço nacional de economia internacional. As imbricações entre os objetos e ações traçam essa formação geográfica que se altera historicamente e conforma um país de grande extensão

\begin{tabular}{llr}
\hline Brito et al., 2019 & ISSN 0104-5490
\end{tabular}


territorial. Resulta primeiramente da variedade dos sistemas naturais ${ }^{1}$, e a partir do século XIX pelas técnicas e pelo processo de industrialização e de globalização que passa a ocorrer no século XX. Emergem a partir da década de 1970 um intenso processo de modernização do país, através de desconcentração de indústrias dinâmicas, e a modernização da agricultura e do setor de serviços - denominado de centrifuguíssimo. E do efeito reverso do centrifugismo com benefícios para a região já dominante.

A criação de um território unificado foi, numa primeira fase, acompanhada de um reforço das lógicas do interesse nacional, enquanto agora a unificação do território constitui um suporte para, exatamente, o contrário, isto é, a extraversão e a fragmentação (2001, p. 254). O Brasil torna-se um espaço nacional da economia internacional, que confronta processos de desterritorialização com uma regulação nacional. Uma diferenciação territorial com áreas mais ou menos globalizadas.

Essas diferenciações que geram desigualdades territoriais derivam de diversos fatores, exigindo o estudo de uma série de variáveis, que perpassam pela compreensão das relações entre zonas de densidade e de rarefação, que têm elementos naturais e artificiais, demográficos, técnicos, objetos e ações. A fluidez e a viscosidade do território, tão necessárias para a circulação de todas as ordens, interessam ao sistema global vigente. Aliado a isso, os espaços de rapidez e de lentidão, definidos pelas técnicas contidas no território, pela divisão do trabalho, pelas relações, pelos transportes, etc.

Temos ainda os espaços luminosos e os espaços opacos, determinados pelas densidades técnicas e informacionais, onde as empresas consideram importante para sua atividade produtiva e gerar maior competitividade, gerando uma hierarquia de lugares. O uso competitivo do território por parte das empresas. E a guerra global entre lugares. Existem ainda os espaços que mandam e os que obedecem, com uma série de condicionantes vinculadas a objetos e ações, sistemas normativos, poder płúblico e privado. E o surgimento de novas lógicas de relação centro-periferia.

No primeiro período que vai até a Segunda Guerra Mundial, havia um policentrismo, com baixa capacidade de controle do território. O segundo período demarca um Brasil unificado com processos de industrialização e um pensamento voltado à construção de uma unidade nacional. Por fim, um terceiro período vinculado com o processo de globalização. Explicam

\footnotetext{
${ }^{1}$ A partir do domínio português, pelo processo de interiorização do território para o sertão, para além dos limites do Tratado de Tordesilhas, da ocupação da bacia Amazônica, da bacia do Prata e a conquista do Acre, predominando a forma de ocupação do território nos primeiros quatro séculos.
} 
que há diminuição da centralidade e a regulação exercida por São Paulo e Brasília diante da globalização, e um aumento da periferia. Propõem uma divisão territorial do Brasil com base no meio técnico científico-informacional e das heranças em quatro partes: uma Região concentrada, formada pelo Sudeste e pelo Sul, o Brasil do Nordeste, o Centro-Oeste e Amazônia.

Estas apresentam uma diferenciação regional da urbanização, substanciada pela lógica da divisão territorial do trabalho. A urbanização das cidades médias e grandes, com inserção de densidades técnicas e de informação. O surgimento do êxodo urbano e também do êxodo rural. As mudanças no consumo e as cidades como lócus para localização de serviços, e distribuição de bens e de mão-de-obra especializada. As cidades grandes, mais atrativas para os pobres que as cidades médias. As metrópoles e sua fluidez, que se situam na forma, função, no dinamismo e sentido, refletindo no padrão da riqueza e da pobreza nas mesmas.

Explicam que cada momento tem uma ordem espacial, que se vincula a uma ordem social. Divisões do trabalho superpostas (produção, circulação e consumo) manifestas no território, devendo ser consideradas as múltiplas escalas entre o local e o global. Ao analisar a divisão do trabalho em sua totalidade, expõem que os circuitos de cooperação, podem ser também circuitos de competição. Daí a dúvida de quem regula quem. Atentam para o processo de privatização do território através do espaço coorporativo, que induz uma lógica territorial. Criticam o negligenciamento do mercado interno e uma circulação desnecessária, que suprime o bem-estar das populações. A instabilidade do território como resultante dos processos supracitados e das oscilações de mercado, com constantes alterações geográficas.

Destarte, emergem áreas com especialização alienígena e alienada, criando um ciclo vicioso de alienação. Desarticulações resultantes do processo de produção, circulação e consumo e desvalorizações e revalorizações do território.

O neoliberalismo como sendo o agente da seletividade no território e produtor de desigualdades para as periferias. Porto-Gonçalves (2012, p. 28) afirma que a emergência "nas-relações-depoder-por-meio-da-tecnologia" comanda a atual fase neoliberal. Moreira (2014, p. 274) afirma que a reforma neoliberal a partir dos anos 1980 "desmonta e desintegra toda essa estratégia de polos de integração do espaço nacional [...], cada empresa atuando em sua gestão privada segundo estratégias territoriais próprias." Sobre o "novo" papel reterritorializador do Estado, Haesbaert (2014) afirma que a partir desse período estão acontecendo mudanças no poder do Estado com o capitalismo neoliberal. 
Isso levou a uma relativa debilitação da sua capacidade, não só de exercer controle externo, sobre fluxos através de suas fronteiras, como também de intervir, internamente, na (re)configuração de regiões e territórios e na redução de desigualdades, sobretudo através do planejamento econômico-territorial em sentido integrado.

[...] A própria retomada de políticas de planejamento regional ou de ordenamento territorial, em países como o Brasil, passou a priorizar escalas mais retritas e, muitas vezes, áreas seletivas e fragmentadas do território (HAESBAERT, 2014, p. 136-137).

O Estado neoliberal atrelado à difusão do meio técnico, cria novas configurações de forças centrípetas e forças centrífugas, que difere dos modelos anteriores em função das condições técnicas e políticas, dispersão das atividades modernas e concentração do comando (político), exercido por São Paulo. E o papel do capital financeiro e da fusão de empresas, com maior rigidez na relação entre as áreas polarizadoras e as áreas polarizadas. Esses fenômenos se emparelham ao afastamento do Estado na adoção de políticas industriais, produtivas e sociais, agravado pela supressão da atuação do cidadão em favor do consumidor. Criticam, portanto, o uso do meio técnico científico-informacional como espaço da racionalidade e a globalização, que emprega recursos sociais atendendo a interesses de empresas privadas.

Moreira (2014) sobre a nova divisão territorial do trabalho e as tendências de regionalização divide o espaço brasileiro em 4 partes (Fronteira biotecnológica, difusão da agroindústria e indústria de não duráveis, complexo agroindustrial, e polígono industrial), que rompem a regionalização de polaridades. Neste contexto "o Brasil está entrando na fase da acumulação de base no complexo agroindustrial” (MOREIRA, 2014, p. 313).

A estrutura industrial concentrada dos anos 1970 se dissemina simplificada pelo Sudeste e Sul para formar o que Diniz designa de polígono industrial [...]. A agroindústria se dilata das áreas sulinas e sudestinas tradicionais até as áreas de cerrado do planalto central para tornar-se uma atividade do Centro-Sul, Centro-Oeste e Nordeste Ocidental. Os polos míneroindustriais se combinam aos de agroindústria de fruticultura irrigada difundidos pelos vales úmidos e de indústrias de bens de consumo de não duráveis migradas do Sudeste e do Sul para formar um novo Nordeste. E o enorme potencial de riqueza genética se alia à tradiação extrativista e familiar-comunitária de subsistência para forma a Amazônia ampliada [...] (MOREIRA, 2014, p. 263-264).

Sendo assim, logo parte-se para discussões sobre a influência político-cientifica e as reflexões sobre o pensamento de Milton Santos. 


\section{A INFLUÊNCIA POLÍTICO-CIENTÍFICA E AS REFLEXÕES SOBRE O PENSAMENTO DE MILTON SANTOS}

Notadamente percebe-se o alcance do pensamento de Milton Santos como sendo seminal para a Geografia Crítica no Brasil e no mundo. Suas obras são amplamente estudadas, resultado de inúmeras teses, e seus conceitos e categorias de análise consubstanciam a base de disciplinas na geografia e demais áreas afins, a exemplo das disciplinas organização do espaço e geografia humana, encontrando expoentes a exemplo dos autores supracitados.

A retomada de uma visão macro do território nacional, considerando que o mesmo apresenta diferenciações regionais essenciais para o entendimento de sua totalidade, é o grande legado de sua contribuição para uma ciência regional. Em que pese o uso de inúmeras variáveis e a conformação de uma unidade de análise socioespacial através do território usado e seus sistemas de objetos e ações. Isso significa poder traçar um elo entre a formação das diferenciações geográficas no Brasil, através das técnicas, mais precisamente do meio técnicocientífico-informacional.

Há uma crença no papel das técnicas na solução dos problemas gerados pela sociedade do meio técnico-científico-informacional, é contraditória já que a política, a ciência, a tecnologia, e a informação agem em favor da globalização perversa. O problema central não é técnico, mas sim de caráter socioespacial, portanto, político, de quem determina e domina o território usado.

\footnotetext{
Mais do que uma lógica das técnicas é diante da afirmação de uma determinada lógica política (e de uma epistemo-lógica) que nos encontramos. [...], até porque é com/contra ela que novas territorialidades vão ter que se haver, até porque sendo uma lógica de dominação pressupõe o controle do dominado (PORTO-GONÇALVES, 2012, p. 30).
}

Cabe alguns questionamentos sobre a abordagem dialética no livro (SANTOS e SILVEIRA, 2011). Não é suficiente tratar das questões da produção, circulação e reprodução de bens e mercadorias. É preciso situá-las dentro da unidade dos contrários no processo de formação do território. Ao retratar o período dos "meios naturais", parece escamotear os conflitos no território, pois a formação do território brasileiro não é pacífica. Dessa forma, essa é uma crítica importante a sua produção, pois a abordagem dialética exige isso, enxergar as contradições no território e a própria formação deste.

A questão da acumulação primitiva também é apenas citada no caso de São Paulo pela cultura do Café. Ainda, o autodinamismo, as forças internas no território, que transformações 
elas operaram e operam? E sua relação com o modo de produção capitalista, entendendo que no Brasil o capitalismo não se deu do mesmo modo que nos países ao Norte. E como podemos explicar as relações entre as forças internas e o atual meio técnico-científico-informacional? É preciso enxergar as contradições existentes na relação capital e trabalho, e os conflitos de classes.

Essas limitações podem ser creditadas ao viés macro abordado na obra, pois para tal estudo das contradições é preciso ir ao chão de fábrica e entender os processos em múltiplas escalas, e a escala micro fica então comprometida. Do mesmo modo, que as mudanças no dinamismo do papel do Estado, refletem mais do que uma variável isolada no território, mas sim, como o elo na formação socioespacial do Brasil.

Destarte, o uso de indicadores de desenvolvimento tradicionais e de qualidade de vida é outra crítica a ser traçada, bem como, não definem o que seria a unidade territorial não desigual para os países subdesenvolvidos. Não há referenciais próprios, apenas a conformação do território brasileiro de modo fragmentado, como um espaço nacional da economia internacional. Fica evidente que o desenvolvimento regional no Brasil é desenvolvimento desigual em favor de áreas mais dinâmicas.

\section{REFERENCIAS}

ELIAS, Denise. Milton Santos: A construção da geografia cidadã. In: El ciudadano, la globalización y la geografía. Homenaje a Milton Santos. Scripta Nova. Revista electrónica de geografía y ciencias sociales, Universidad de Barcelona, vol. VI, núm. 124, 30 de septiembre de 2002.

HAESBAERT, Rogério. Viver no limite: território e multi/transterritorialidade em tempos de in-segurança e contenção. Rio de Janeiro: Bertrand Brasil, 2014.

MOREIRA, Ruy. A formação espacial brasileira: contribuição crítica aos fundamentos espaciais da geografia do Brasil. $2^{\mathrm{a}}$ ed., Rio de Janeiro: Consequência, 2014.

PORTO-GONÇALVES, Carlos W. A reinvenção dos territórios na América Latina/Abya Yala. México: Universidade Nacional Autónoma de México, 2012. 
RIBEIRO, Wagner Costa. Milton Santos: aspectos de sua vida e obra. In: El ciudadano, la globalización y la geografía. Homenaje a Milton Santos. Scripta Nova. Revista electrónica de geografía y ciencias sociales, Universidad de Barcelona, vol. VI, núm. 124, 30 de septiembre de 2002.

SANTOS, Marie-Hélène Tiercelin. Biografía Milton Santos (1926-2001). Por Marie-Hélène Tiercelin dos Santos com títulos de Jacques Levy. Disponível em: http://miltonsantos.com.br/. Acesso em: 21 nov.2017.

SANTOS, Milton; SILVEIRA, Maria Laura. O Brasil: território e sociedade no início do século XXI, Record, Rio de Janeiro, 2001.

SANTOS, Milton. Sociedade e Espaço: Formação Espacial como Teoria e como Método. Antipode, nº 1, vol. 9, jan./fev. de 1977.

. Por uma geografia nova, HUCITEC-EDUSP, São Paulo, 1978.

. O espaço dividido, Livraria Editora Francisco Alves, Rio de Janeiro, 1978.

. Espaço e Método, Nobel, São Paulo, 1985.

. Metamorfoses do Espaço Habitado, HUCITEC, São Paulo, 1988.

. A Urbanização Brasileira, Hucitec, São Paulo, 1993.

.Técnica, Espaço, Tempo: Globalização e meio técnico-científico informacional, Hucitec, São Paulo, 1994.

. A Natureza do Espaço. Técnica e Tempo. Razão e Emoção. Hucitec, São Paulo, 1996.

. Por uma outra globalização. Do pensamento único à consciência universal. Record, Rio de Janeiro, 2000. 
SILVA, Maria Auxiliadora da. Milton Santos: a trajetória de um mestre. In: El ciudadano, la globalización y la geografía. Homenaje a Milton Santos. Scripta Nova. Revista electrónica de geografía y ciencias sociales, Universidad de Barcelona, vol. VI, núm. 124, 30 de septiembre de 2002. Disponível em: http://www.ub.es/geocrit/sn/sn-124.htm. Acesso em: 21 nov.2017. 